\title{
AC 2008-1139: SURVEY OF ENGINEERING MECHANICS IN CIVIL ENGINEERING CURRICULA
}

Bridget Wadzuk, Villanova University

Assistant Professor Water Resources Engineer

David Dinehart, Villanova University

Associate Professor Structural Engineer

Edward Glynn, Villanova University

Assistant Professor Geotechnical Engineer

Shawn Gross, Villanova University

Associate Professor Structural Engineer

Frank Hampton, Villanova University

Assistant Professor Structural Engineer 


\title{
Survey of Engineering Mechanics in Civil Engineering Curricula
}

\begin{abstract}
Newtonian mechanics provides most of the core concepts that enable civil engineering students to identify, formulate, and solve engineering problems. The Department of Civil and Environmental Engineering at Villanova University is investigating how to better present material in the core mechanics courses to better meet the educational needs of the students and improve learning. The core sequence in mechanics at Villanova University consists of five courses: Statics/Dynamics, Mechanics of Solids, Civil Engineering Materials, Fluid Mechanics and Fluid Mechanics Laboratory. To determine the current state of practice in mechanics education, the authors conducted a survey of civil engineering mechanics curricula at fifty universities. Civil engineering curricula present mechanics in a variety of courses and formats; the survey evaluated format (e.g. lecture, laboratory, recitation, or workshop), total credits in the curriculum, total credits devoted to mechanics courses, lecture hours, laboratory hours, whether the courses were required or elective, administrating department and the school's classification and profile. Additionally innovative practices and combined courses were noted.
\end{abstract}

Survey information was acquired via the school's respective web sites to develop a database on engineering mechanics. The survey results show that while the mechanics courses and sequencing are generally similar, there exists some variation among programs. This paper presents the detailed results of the survey and describes the major similarities and differences identified. Innovative and unique practices among the programs surveyed are identified, and recommendations are provided to initiate mechanics curricula change.

\section{Introduction}

The civil engineering curriculum, as well as that of related disciplines such as mechanical engineering, is based on a few fundamental courses in mechanics. Herein, the mechanics courses are defined as Statics, Dynamics, Mechanics of Solids, Materials and Fluid Mechanics. These core courses have recently been subject to curricular changes to make concepts more accessible and integrated with later courses and the practice of civil engineering ${ }^{1,2,3}$. In line with current trends, the Department of Civil and Environmental Engineering at Villanova University recognized that the mechanics courses could be a place where innovative teaching and learning strategies could be implemented. Before revising the curriculum, a survey of schools was completed to see what novel practices are being used to determine if there is some consensus over what mechanics topics are considered important and to identify the state of practice in civil engineering curricula.

\section{Methods}

A survey was conducted in summer 2007 to evaluate how other civil engineering programs present the mechanics topics (note: the term "topic areas" is used to denote the mechanics concepts that are covered in traditional mechanics courses, "course" is used to denote where the concepts are packaged together). The survey was conducted by the authors by searching each 
institution's website; using websites was preferred as opposed to sending out a survey request to the different programs due to time constraints. Websites provide a wealth of information as most institutions have program curricula, course descriptions and course schedules publicly available; for some schools and courses, course content, such as a syllabus, is available.

Fifty programs, including Villanova University's, were surveyed (Appendix 1). The programs were chosen based on if they were considered to be a peer institution, known for innovative practices, local to Villanova University or highly ranked undergraduate programs. The assessed institutions are diverse with public and private, research and teaching oriented and large and small institutions all represented. Forty-six of the fifty assessed programs grant a Bachelor of Science in Civil Engineering or Bachelor of Science in Engineering and are ABET accredited. The other four schools grant Bachelor of Science in Engineering or similar degrees with concentrations in civil engineering or related fields.

The information collected from each program was:

1) total credits in the curriculum

2) total credits in the mechanics courses

3) degree title

4) innovative aspects

5) general notes on the curriculum

6) required or elective status of each mechanics course

7) credits per course

8) lecture hours

9) laboratory hours

10) semester placement within the curriculum

11) department that administers the course

A database was developed that listed each school, general information including items 1 - 5 above. Each of the five mechanics topic areas (Statics, Dynamics, Mechanics of Solids, Materials and Fluid Mechanics) was assessed including items 6 - 11 above.

Different institutions have varying accounting procedures in terms of credit counting and hours for each course. As much information as possible was culled from the websites, but when details were not readily available assumptions were made. The total credits in the curriculum and mechanics courses were generally available. There was some variability in credits if a civil engineering program had tracks (e.g. structural or environmental); a note was made in the survey if there was a tracked curriculum. A course was only deemed required if all students in the program were required to take the course, regardless of track. The semester was assumed to include fourteen weeks of classes, unless otherwise noted; institutions on a quarter system were adjusted to the semester system. Each class was assumed to be 50 minutes (if classes were listed on the hour, e.g. 10:30 - 11:30), 75 minutes (if classes were listed on the hour and a half, e.g. 10:00 - 11:30) or 170 minutes (if classes were listed on the three hour, e.g. 8:30-11:30), unless otherwise noted. If classes were combined (e.g. Statics and Dynamics), then an assumption was made of the fraction of the class devoted to the different topic areas (e.g. in a four credit Statics and Dynamics class at Villanova University three credits were assigned to Statics and one credit 
was assigned to Dynamics); this assumption was based on the course description and a syllabus, if available. Similarly, if the lecture portion and lab portion of a subject were combined into one class, the credits were distributed according to course description, course syllabus and schedule. An example of the information collected is displayed in Table 1.

Table 1: Example of collected survey information. Sem/Yr - Semester/Year; Spr - spring, Fa - fall, $\mathrm{Fr}$ - freshman, So - sophomore, Jr - junior, EGR - general engineering, CE - civil engineering, ME mechanical engineering.

\begin{tabular}{|c|c|c|c|c|c|c|c|}
\hline \multicolumn{3}{|l|}{ School } & \multicolumn{5}{|c|}{ ABC University } \\
\hline \multicolumn{3}{|l|}{ Department } & \multicolumn{5}{|c|}{ Civil Engineering } \\
\hline \multicolumn{3}{|l|}{ Degree } & \multicolumn{5}{|c|}{ Bachelor of Science in Civil Engineering } \\
\hline \multicolumn{3}{|c|}{ Total \# Credits (Overall Curriculum) } & \multicolumn{5}{|l|}{136} \\
\hline \multicolumn{3}{|c|}{$\begin{array}{l}\text { Important Notes on General Curriculum (Choices of } \\
\text { Tracks, etc) }\end{array}$} & \multicolumn{5}{|c|}{ One course in each of five areas then choose electives } \\
\hline \multicolumn{3}{|c|}{ Total \# Credits (Mechanics Curriculum) } & \multicolumn{5}{|l|}{16} \\
\hline \multicolumn{3}{|c|}{$\begin{array}{l}\text { Innovative Aspects of Mechanics Curriculum That } \\
\text { Merits Further Investigation (Integrated Courses, etc.) }\end{array}$} & \multicolumn{5}{|c|}{ None noted } \\
\hline Subject & Required & Notes & Sem/Yr & $\begin{array}{c}\text { Dept } \\
\text { Taught } \\
\text { By }\end{array}$ & $\begin{array}{c}\# \\
\text { Credits }\end{array}$ & $\begin{array}{l}\text { Total Student } \\
\text { Lecture } \\
\text { Hours }\end{array}$ & $\begin{array}{c}\text { Total Student } \\
\text { Laboratory } \\
\text { Hours }\end{array}$ \\
\hline Statics & Yes & $\begin{array}{l}\text { Combined course with } \\
\text { dynamics (estimated } 3 / 4 \\
\text { statics, } 1 / 4 \text { dynamics) }\end{array}$ & $\mathrm{Spr} / \mathrm{Fr}$ & EGR & 3 & 35 & 0 \\
\hline Dynamics & Yes & $\begin{array}{l}\text { Combined course with } \\
\text { dynamics (estimated } 3 / 4 \\
\text { statics, } 1 / 4 \text { dynamics) }\end{array}$ & $\mathrm{Spr} / \mathrm{Fr}$ & EGR & 1 & 12 & 0 \\
\hline $\begin{array}{l}\text { Mechanics of } \\
\text { Solids }\end{array}$ & Yes & Meets 4 days per week & $\mathrm{Fa} / \mathrm{So}$ & $\mathrm{CE} / \mathrm{ME}$ & 4 & 47 & 35 \\
\hline Materials & Yes & $\begin{array}{l}\text { Combined Lecture/Lab } \\
\text { course }\end{array}$ & Spr/So & $\mathrm{CE}$ & 4 & 35 & 35 \\
\hline Fluid Mechanics & Yes & $\begin{array}{l}\text { Combined Lecture/Lab } \\
\text { course }\end{array}$ & $\mathrm{Spr} / \mathrm{Jr}$ & $\mathrm{CE}$ & 4 & 35 & 35 \\
\hline
\end{tabular}

\section{Results}

The basic results are presented in Table 2 for the percent of schools surveyed that required a mechanics course (e.g. Statics), the percent of schools that required the course and was not combined with another mechanics course (stand-alone), the percent that required a laboratory with the specific mechanics course and the percent of schools that required a laboratory as an individual course. More in-depth results for each individual topic area are presented below. As the survey proceeded, the most interesting data points to the authors were whether the course was required, if it required a lab, the number of hours that covered the course material, the administrating department and the type of institution. As noted in Appendix 1, the authors used The Carnegie Classification of Institutions of Higher Learning ${ }^{4}$ to categorize schools. 
Table 2: Summary of mechanics courses for surveyed schools.

\begin{tabular}{|l|c|c|c|c|}
\hline & \% required* & \% stand-alone & \% lab required & \% lab stand-alone \\
\hline Statics & 94 & 58 & 10 & 0 \\
\hline Dynamics & 72 & 62 & 2 & 0 \\
\hline Mechanics of Solids & 90 & 70 & 29 & 4 \\
\hline Materials & 70 & 64 & 83 & 20 \\
\hline Fluid Mechanics & 88 & 80 & 67 & 16 \\
\hline $\begin{array}{l}\text { * a course is considered required when it is an independent course or a major portion of a } \\
\text { combined course }\end{array}$
\end{tabular}

$\underline{\text { Statics }}$

All but three schools required Statics as either an independent course or a major portion of a combined course. Statics was most often combined with Dynamics or Mechanics of Solids. For programs that did not require Statics, subject matter from Statics is included in the required Physics and Mechanics of Solids courses, or as part of a highly integrated fundamental mechanics course.

Statics is usually taught in the sophomore year, as most engineering programs have a common or general first year. The civil engineering department administered Statics at approximately $30 \%$ of the schools; the remaining schools administered Statics as a general engineering course or through the mechanical engineering or engineering mechanics departments. There is no apparent trend between the administrating department and school size, type (private/public) or focus (research, master's, baccalaureate, etc.). The total number of lecture hours ranged from nine to 47 , with an average of 32 hours; $60 \%$ of the schools covered Statics in 33 to 39 hours. Five programs had a laboratory component in the Statics class according to the published course descriptions.

Five programs combined Statics with Dynamics and six programs combined Statics with Mechanics of Solids. Some other examples of combinations are: Statics with linear algebra and matrix methods; Statics with Dynamics and elementary aspects of Mechanics of Solids; an engineering mechanics course that includes concepts from Statics, Mechanics of Solids and Materials with a laboratory component; a mechanics course that includes components from Statics, Dynamics, Mechanics of Solids and Materials; a course with approximately $25 \%$ related to Statics, and the rest of the class has applications in Mechanics of Solids, Materials and Fluid Mechanics.

\section{Dynamics}

Dynamics was required by $72 \%$ of the surveyed institutions as either an independent course or a major component of a combined course (typically combined with Statics). Ten of the thirteen programs that do not require Dynamics are research focused institutions; at several of these schools Dynamics is available as an elective or may be required by one track within the civil engineering department. One institution requires Dynamics (administered through mechanical engineering) however not until the spring semester of the fourth year. The programs that require Dynamics usually sequence it within the second year. Approximately $30 \%$ of the programs 
administer Dynamics through the civil engineering department. Generally, the department that administers Statics also administers Dynamics. The total number of lecture hours ranged from twelve to 53, with an average of 34 hours; 55\% of the schools covered Dynamics between 33 and 39 hours. Only one program has a laboratory associated with Dynamics.

\section{$\underline{\text { Mechanics of Solids }}$}

Mechanics of Solids was required by $90 \%$ of the surveyed schools as either an independent course or a major component of a combined course (typically combined with Statics). For the schools that do not require Mechanics of Solids, the course has elective status or is required for a specific track. The course is generally required in the second year. The total number of lecture hours ranges from eleven to 70 with an average of 37 hours; $65 \%$ of the schools covered Mechanics of Solids in 33 to 39 hours. Thirteen programs have a laboratory component that is integrated with the course in some capacity, ranging from five to 39 hours. The civil engineering department administered the course at approximately $50 \%$ of the surveyed institutions. The schools that have the course administered by the general engineering department tend to be smaller, private institutions (twelve of the sixteen schools). Six of the seven schools that have an engineering mechanics department administered Mechanics of Solids.

\section{$\underline{\text { Materials }}$}

There are two general categories of Materials courses found in civil engineering curricula: behavior of materials and material science. The behavior of materials type courses focus on properties and behavior of steel, concrete and wood, while the material science type courses focus on the chemistry aspects of materials; the survey focuses on the former. A Materials course was required by $70 \%$ of the surveyed programs. For the programs that do not require Materials, some required a materials science course or had Materials as an elective, however seven schools did not offer the course at all. Many of the available Materials courses were largely, or solely, laboratory based. The lecture hours ranged from zero to 45 with an average of 24 hours. The laboratory hours ranged from zero to 80 with an average of 28 hours. The civil engineering department administered the course at approximately $85 \%$ of the schools. The remaining $15 \%$ of schools with a Materials course administered the course through the general engineering department; these schools tended to be private, half are research focused institutions and the other half are either exclusively undergraduate or very high undergraduate institutions.

\section{Fluid Mechanics}

Fluid mechanics is a required course, either as an independent course or a major component of a combined course, at $88 \%$ of the surveyed institutions. When combined with another topic, Fluid mechanics is combined with thermodynamics or hydraulics. When combined with hydraulics, the fluid mechanics portion appears to range from basic concepts to approximately half the topics covered in the course. The course is generally available in the third year. Fourteen of the programs that require Fluid Mechanics do not have a laboratory component, either as part of the course or required as a separate course. There is no apparent trend of control or focus of schools that do not require a Fluid Mechanics laboratory or a Fluid Mechanics laboratory component. Eighteen of the programs that require Fluid Mechanics include the laboratory component with 
the lecture portion. The remaining programs have a separate, required laboratory class; four of these programs offer the laboratory in a different semester than the lecture class. Generally, the Fluid Mechanics courses are three credits with an additional credit for the laboratory, either as an individual class or as part of the lecture class. The total number of lecture hours ranged from twelve to 70 with an average of 34 hours; $65 \%$ of the schools covered Fluid Mechanics between 33 and 39 hours. The civil engineering department administered the course in approximately $75 \%$ of the schools. The remaining schools administered Fluid Mechanics through the general engineering and mechanical engineering departments; only two schools with engineering mechanics departments administered this course.

\section{Discussion}

The survey results indicate that the mechanics courses are similar among the assessed programs, although there were some variations. Some of the main variations were in how courses were combined, inclusion of labs and administration of the courses. Generally, a traditional civil engineering curriculum with discrete courses in each of these topic areas is still prevalent, but there seems to be a move towards changing this model.

It is clear that Statics is considered an important topic, but it also is the topic with the most variability in its presentation. Due to the fundamental nature of Statics' subject matter, some programs have combined it with classes that build directly on this subject matter (i.e. Dynamics and Mechanics of Solids), while other programs take the opportunity to move away from the traditional methods of teaching Statics to include real life applications, laboratories and studio experiences. The reason for innovative and integrated techniques is twofold: to help students see the connection between the fundamental concepts and engineering design and to excite the students early in the college experience ${ }^{2}$.

Mechanics of Solids and Fluid Mechanics are both deemed as important topics, with 90 and $88 \%$ of programs requiring these courses, respectively. The more integrated curricula took advantage of the natural connections between Statics and Mechanics of Solids, however few programs drew connections between Statics and Fluid Mechanics or Mechanics of Solids and Fluid Mechanics. Some examples are introducing some Fluid Mechanics concepts in the first engineering mechanics course and offering a continuum mechanics course that combines Fluid and Solid Mechanics concepts. Both Mechanics of Solids and Fluid Mechanics have a laboratory component, although it is more prevalent with Fluid Mechanics.

Dynamics and Materials are the two topics within mechanics that are viewed as less important with regards to a requirement in the civil engineering curriculum. These topic areas tend to be more directed at specific subjects within the civil engineering curriculum and some schools may opt out of requiring these courses for all civil engineering students to add flexibility to the curriculum and reduce required credits.

There is a trend that programs are moving to a track system. Sixteen of the surveyed schools have track systems; schools without a formal track system do tend to let students specialize in an area with senior level electives and design projects. The most common two tracks are environmental and structural, although other common tracks are in transportation, water 
resources and construction management. Fourteen of the sixteen schools that offer tracks are research focused programs. Research focused schools may have more resources to provide the wide variety of courses needed to allow students to choose a track curriculum.

Another interesting observation is that 21 of the 33 research focused programs have 130 or less total number of credits (on the semester system) in the civil engineering curriculum, while only three of the sixteen specialized, baccalaureate or master's focused programs have 130 or less total number of credits in the civil engineering curriculum. Despite this difference in credit allotment among institutions, there is no apparent trend as to the control or focus of schools leading innovative changes in the civil engineering teaching model, such as integrated and applied classes. Some programs are reformatting the mechanics sequence, while other schools are changing the presentation of the entire curriculum with problem based learning, clinics and studio labs.

\section{The Next Steps}

The Department of Civil and Environmental Engineering at Villanova University undertook this survey in preparation for making educated adjustments to its existing curriculum. In addition to this survey, a prioritized catalog of engineering mechanics topics was developed. The catalog looks at each course (e.g. Statics) and breaks it into the specific subjects within the course (e.g. two-dimensional particle equilibrium and equivalent force systems). Each subject within all of the mechanics courses was assessed for use in later courses within the civil engineering curriculum and importance for a civil engineering graduate. The Department has taken the information collected from the survey and catalog to develop a sequence of mechanics courses that incorporates the most important topic areas with innovative practices, such as integration of topic areas across disciplines, integration of lecture and laboratory experiences and applications to real world examples. The new mechanics sequence will be launched in fall 2009.

The authors have found the survey to provide a wealth of information and it played an important role in the development of a reformed mechanics curriculum. Future curriculum changes can benefit from this survey and surveys directed at specific ideas, such as problem based learning and service learning. The survey provides a comprehensive view of common practices at peer institutions and promotes sharing effective practices.

\section{Acknowledgement}

This research was partially supported by a Villanova Institute for Teaching and Learning grant. 
Appendix 1: List of surveyed institutions. All designations and information are taken from The Carnegie Classification of Institutions of Higher Education ${ }^{4}$. The enrollment profile classification is based on the full-time enrollment percentages of the institution.

\begin{tabular}{|c|c|c|c|c|}
\hline Institution & Control & Basic & Enrollment & $\begin{array}{c}\text { Enrollment } \\
\text { Profile } \\
\end{array}$ \\
\hline Bucknell University & Private & $\mathrm{Bac}$ & 3609 & VHU \\
\hline California Polytechnic State University & Public & ML & 19003 & VHU \\
\hline University of California - Berkeley & Public & RU & 32803 & MU \\
\hline Carnegie Mellon University & Private & RU & 9803 & MU \\
\hline Case Western Reserve University & Private & RU & 9095 & MGP \\
\hline Catholic University of America & Private & RU & 5987 & MU \\
\hline Cooper Union & Private & $\mathrm{Bac}$ & 972 & VHU \\
\hline Cornell University & Private & RU & 19518 & MU \\
\hline Dartmouth College & Private & RU & 5704 & MU \\
\hline University of Dayton & Private & RU & 10495 & MU \\
\hline Univeristy of Delaware & Public & RU & 21238 & $\mathrm{HU}$ \\
\hline Drexel University & Private & RU & 17656 & MU \\
\hline Duke University & Private & RU & 12770 & MGP \\
\hline Embry-Riddle Aeronautical University & Private & MM & 4788 & VHU \\
\hline Georgia Institute of Technology & Public & RU & 16841 & MU \\
\hline Harvey Mudd College & Private & $\mathrm{Bac}$ & 721 & ExU4 \\
\hline University of Illinois - Urbana-Champaign & Public & RU & 40687 & MU \\
\hline Iowa State University & Public & RU & 26830 & $\mathrm{HU}$ \\
\hline Lafayette College & Private & $\mathrm{Bac}$ & 2303 & ExU4 \\
\hline Lehigh University & Private & RU & 6641 & $\mathrm{HU}$ \\
\hline Loyola Marymount University & Private & ML & 8770 & MU \\
\hline Manhattan College & Private & $\mathrm{MM}$ & 3299 & VHU \\
\hline Marquette University & Private & RU & 11510 & MU \\
\hline University of Maryland & Public & RU & 34933 & $\mathrm{HU}$ \\
\hline University of Massachusetts - Amherst & Public & RU & 24646 & $\mathrm{HU}$ \\
\hline University of Massachusetts - Lowell & Public & DRU & 11089 & $\mathrm{HU}$ \\
\hline Merrimack College & Private & $\mathrm{Bac}$ & 2352 & VHU \\
\hline Michigan Technological University & Public & RU & 6527 & $\mathrm{HU}$ \\
\hline Massachusetts Institute of Technology & Private & RU & 10320 & MGP \\
\hline University of Notre Dame & Private & RU & 11479 & MU \\
\hline University of Pennsylvania & Private & RU & 23305 & MU \\
\hline Pennsylvania State University & Public & RU & 41289 & $\mathrm{HU}$ \\
\hline University of Pittsburgh & Public & RU & 26731 & MU \\
\hline Purdue University & Public & RU & 40108 & $\mathrm{HU}$ \\
\hline
\end{tabular}




\begin{tabular}{|c|c|c|c|c|}
\hline Rose-Hulman Institute of Technology & Private & Spec & 1904 & VHU \\
\hline Rowan Univeristy & Public & ML & 9688 & VHU \\
\hline Rensselaer Polytechnic Institute & Private & RU & 6696 & $\mathrm{HU}$ \\
\hline Rutgers University & Public & RU & 34696 & $\mathrm{HU}$ \\
\hline Stanford University & Private & RU & 18836 & MGP \\
\hline Swarthmore College & Private & $\mathrm{Bac}$ & 1474 & ExU4 \\
\hline Syracuse University & Private & RU & 18247 & MU \\
\hline Temple University & Public & RU & 33551 & $\mathrm{HU}$ \\
\hline University of Texas at Austin & Public & RU & 50377 & MU \\
\hline Tufts University & Private & RU & 9690 & $\mathrm{MU}$ \\
\hline US Air Force Academy (Col. Springs) & Public & $\mathrm{Bac}$ & 4266 & $\overline{\text { ExU4 }}$ \\
\hline US Military Academy (West Point) & Public & $\mathrm{Bac}$ & 4183 & ExU4 \\
\hline US Naval Academy (Annapolis) & Public & $\mathrm{Bac}$ & 4349 & ExU4 \\
\hline Villanova University & Private & ML & 10610 & $\mathrm{HU}$ \\
\hline $\begin{array}{c}\text { Virginia Polytechnic Institute and State } \\
\text { University }\end{array}$ & Public & RU & 27619 & $\mathrm{HU}$ \\
\hline Washington Univerisity - St. Louis & Private & RU & 13210 & MU \\
\hline $\begin{array}{l}\text { Bac - Baccalaureate } \\
\text { MM - Master's Medium } \\
\text { ML - Master's Larger } \\
\text { RU - Research University } \\
\text { DRU - Doctoral Research University } \\
\text { Spec - Special Focus Institution }\end{array}$ & \multicolumn{4}{|c|}{$\begin{array}{l}\text { ExU4 - Exclusively undergraduate four year } \\
\text { VHU - Very high undergraduate } \\
\text { HU - High undergraduate } \\
\text { MU - Majority undergraduate } \\
\text { MGP - Majority graduate/professional }\end{array}$} \\
\hline
\end{tabular}

\section{Bibliography}

1. Kraige, G. and D.H. Morris (2000), "Recent curriculum changes in engineering science and mechanics at Virginia Polytechnic Institute and State University.” The International Journal of Engineering Education, 16:5:436440.

2. Klosky, J., D. Hains, T. Johnson, J. Bruhl, J.B. Erickson, and J. Richards (2007), "An integrated approach for engineering mechanics and design." Proceedings of the 2007 American Society for Engineering Education Annual Conference and Exposition.

3. Nocito-Gobel, J., S. Daniels, G. Broderick, M. Collura, and R. Stanley (2007), "Civil and mechanical engineering students learning mechanics in a multidisciplinary engineering foundation spiral." Proceedings of the 2007 American Society for Engineering Education Annual Conference and Exposition.

4. "The Carnegie Classification of Institutions of Higher Education." The Carnegie Foundation for the Advancement of Teaching (2007). http://www.carnegiefoundation.org/classifications/ 